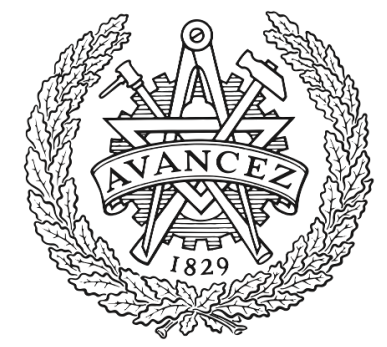

CHALMERS

UNIVERSITY OF TECHNOLOGY

\title{
Load exposure of osseointegrated implants for transfemoral limb prosthesis during running
}

Downloaded from: https://research.chalmers.se, 2023-04-26 00:14 UTC

Citation for the original published paper (version of record):

Thesleff, A., Ludvigsson, S., Ohr, E. et al (2018). Load exposure of osseointegrated implants for transfemoral limb prosthesis during running. Proceedings of the Annual International Conference of the IEEE Engineering in Medicine and Biology Society, EMBS, 2018-July: 1743-1746.

http://dx.doi.org/10.1109/EMBC.2018.8512592

N.B. When citing this work, cite the original published paper. 


\title{
Load exposure of osseointegrated implants for transfemoral limb prosthesis during running
}

\author{
Alexander Thesleff, Graduate Student-Member IEEE, Sofie Ludvigsson, Emilia Öhr, Max Ortiz- \\ Catalan, Member IEEE
}

\begin{abstract}
Direct skeletal attachment of lower limb prostheses ensures direct load transfer between the prosthetic leg and the skeleton. Knowledge of the load characteristics at the boneimplant interface during high-loading activities is needed to understand the limitations of current implant systems, as well as to inform their future development. The present study estimates the load scenario at the bone-implant interface of a transfemoral amputee while running with kinematic symmetry between the prosthetic and the intact limbs corresponding to that of an ablebodied subject. Kinematic symmetry was used as this represents the ultimate aim of advanced bionic legs. Kinematic data and ground reaction forces from a running trial of an able-bodied subject were matched to a musculoskeletal model of a transfemoral amputee. The joint reaction forces at the boneimplant interface were calculated using inverse dynamics. The normalized peak forces and moments during a single gait cycle were calculated to $153 \%$ BW (body weight) / -14.8\% BWm, 186 $\% \mathrm{BW} / 16.2 \% \mathrm{BWm}$ and $56.8 \% \mathrm{BW} /-18.7 \% \mathrm{BWm}$ for the $\mathrm{x}-$ (anterior), $y$ - (longitudinal), and z-axis (lateral-medial), respectively. These findings can potentially be used as design input for future implant systems and external safety devices.
\end{abstract}

\section{INTRODUCTION}

Direct skeletal attachment of lower limb prostheses, provides a mechanically stable connection and direct load transfer between the external prosthesis and the skeleton [1]. The general recommendation for users with osseointegrated prosthetic systems for lower limbs is to avoid activities which subject the intramedullary implant and the residual bone to high forces and moments. Exposing the implant and the bone to excessive loads could potentially lead to fractures in the bone, the implant system, or the interface between the two. In an attempt to quantify the fracture load, Welke et al. performed four-point-bending tests on eight human cadaver femora implanted with bone-anchored implants, and reported bone fractures at $100.4 \pm 38.5 \mathrm{Nm}$ [2].

An understanding of the load characteristics of the implant during high-loading activities is needed in order to understand

"Research supported by research grants from the Swedish Foundation for Strategic Research, European Commission (H2020: DeTOP), Stiftelsen Promobilia, and VINNOVA.

All authors are with Biomechatronics and Neurorehabilitation Laboratory, Department of Electrical Engineering, Chalmers University of Technology, 412 96, Gothenburg Sweden.

Alexander Thesleff and Assoc. Prof. Max Ortiz-Catalan are with Integrum AB, 43137 Mölndal Sweden. the limitations of current implant systems and to be able to design stronger implant systems in the future. By simulating five different scenarios of a fall, the loading scenario at four distances $118 \mathrm{~mm}$ - $307 \mathrm{~mm}$ above the knee joint was evaluated in studies by Welke et al. [3] and by Schwarze et al. [4]. They reported peak resultant forces and moments normalized with respect to body weight (BW) with a total range of $149 \pm 37 \% \mathrm{BW}-445 \pm 71 \% \mathrm{BW}$ and $12 \pm 4-25 \pm$ $24 \% \mathrm{BWm}$, respectively for the five falling scenarios.

Another potentially high-loading activity is running. However, limited published information exists regarding the loading characteristics for transfemoral amputees (TFA) while running. Burkett et al. reported peak vertical ground reaction forces corresponding to $250 \% \mathrm{BW}$ while running at maximum speed for a single unilateral TFA athlete, as part of a case study to evaluate the symmetry between the prosthetic and the anatomical limb during the course of the running gait [5]. In another case study on a unilateral TFA, Mauroy et al. reported peak vertical ground reaction forces of $310 \% \mathrm{BW}$ and $380 \%$ $\mathrm{BW}$ at $2.2 \mathrm{~m} / \mathrm{s}$ and $4.7 \mathrm{~m} / \mathrm{s}$ running speed respectively [6]. To the authors' knowledge, direct load measurements of the forces and moments above the prosthetic knee joint have not been recorded from TFAs during running. However, such measurements have been recorded from TFAs during various types of walking and stair climbing [7]-[10].

The goal for a lower limb prosthesis is to restore full functionality of a lost lower extremity. This would enable the user to ambulate with the prosthetic limb, with kinematic symmetry between the anatomical and the prosthetic limb similar to that of able-bodied individuals. In this study, we characterized the loads introduced at the bone-implant interface in a TFA with a bone-anchored prosthesis when running with gait symmetry corresponding to an able-bodied individual. We adapted a generic musculoskeletal model of an able-bodied subject developed by Hamner et al. [11] into a generic model of a TFA using the freely available software OpenSim [12]. The model was then matched to a publicly available data set collected by Hamner et al. [11], containing

Sofie Ludvigsson and Emilia Öhr are with Biomedical Engineering Department of Lund Institute of Technology, 22363 Lund, Sweden.

Alexander Thesleff, (+46 704 027626; thesleff@chalmers.se)

Sofie Ludvigsson, (sofie.ludvigsson@hotmail.com)

Emilia Öhr, (emilia.ohr@gmail.com)

Assoc. Prof. Max Ortiz-Catalan, (maxo@chalmers.se) 
kinematic and ground reaction force data from a running trial of an able-bodied subject.

\section{METHOD}

\section{A. Adaptation of the musculoskeletal model}

The original model developed by Hamner et al. consists of 92 musculotendon actuators which characterize 76 muscles of the lower extremities and torso [11]. The coordinate system convention followed in this work follows that of the original model where the $\mathrm{x}$-direction represents the posterior-anterior direction (positive towards the anterior), the y-direction represents the vertical direction (positive upwards), and the zdirection represents the medio-lateral direction (positive towards the right side of the body). The model was adapted to better represent the anatomy of a unilateral TFA with a boneanchored lower limb prosthesis attached to the amputated femur. A weld joint with zero degrees of freedom was introduced at the level of the bone-anchored implant on the left femur at a location $190 \mathrm{~mm}$ distal to the left hip joint center and $187 \mathrm{~mm}$ proximal to the left knee joint center (Fig 1.). The implant joint and its local coordinate system was aligned to match the orientation of the long axis of the femur at the level of the amputation. This resulted in a slight negative $\left(5^{\circ}\right)$ orientation around the global $\mathrm{x}$-axis and positive $\left(7^{\circ}\right)$ orientation around the global z-axis at the default anatomic position. All other joints were kept unchanged from the original model. The masses, mass-centers and inertial properties of the body segments of the left lower limb were updated to match those of a TFA with a bone-anchored prosthesis and a prosthetic foot. The visual geometric representations of the body segments of the left lower limb were modified to reflect the transfemoral amputation and the addition of the bone-anchored prosthesis. All muscles of the left lower limb with proximal insertion points more distal than the pelvis were removed. Of the remaining muscles, those having a distal insertion point distal to the amputation level were modified by redirecting the individual geometry path for each muscle, ensuring that the distal insertion point was at the distal end of the amputated femur to resemble a myodesis.

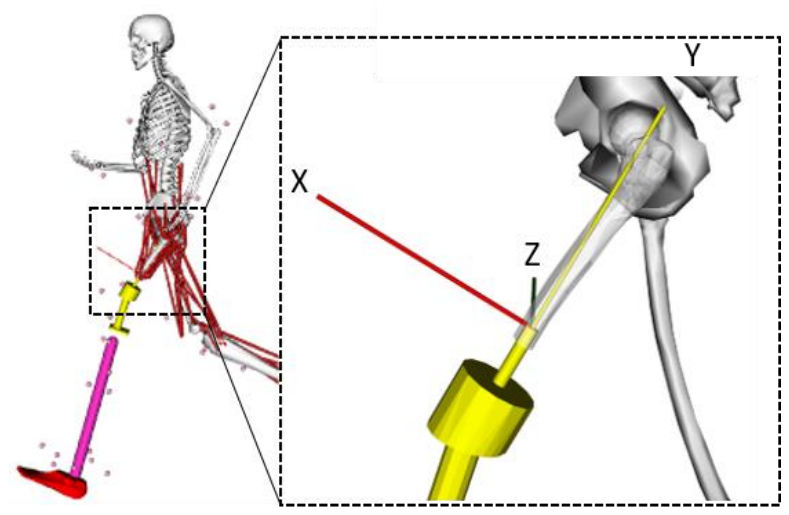

Figure I. Visual representation of the scaled full body musculoskeletal model of a TFA with the local coordinate system for the bone-implant interface indicated. The pink dots represent the virtual markers and the red lines represent the geometric paths of the muscles included in the model.

\section{B. Experimental data}

The experimental data consisted of marker trajectories, ground reaction forces and moments from a running trial of a single able-bodied male subject (height $1.83 \mathrm{~m}$, and mass $65.9 \mathrm{~kg}$ ) running on a treadmill at $3.96 \mathrm{~m} / \mathrm{s}$ [11]. The generic model was equipped with a virtual marker set identifying anatomical landmarks, corresponding to the same landmarks as the marker set of the subject in the running trial. The generic model was scaled to match the distances between the virtual marker set in the generic model to the corresponding markers on the subject. Masses of individual body segments and the total mass was also scaled to match the subject.

\section{Matching experimental data with musculoskeletal model}

Kinematic data in the form of marker trajectories from the running trial was used by an inverse kinematics algorithm to align the joint angles of the scaled model to corresponding values from the running trial. Based on the ground reaction force data from the running trial, the single gait cycle exhibiting the largest vertical force components was identified and chosen for further analysis. Joint actuators were introduced in all joints to ensure that the musculoskeletal model could track the kinematic trajectories when including external forces in the form of ground reaction force and moment data from the running trial corresponding to the identified gait cycle. A built-in residual reduction algorithm (explained in more detail in [12]) was run in order to minimize the non-physical residual forces and moments required to fulfil Newton's second law of motion while keeping trajectory errors to a minimum. A recommended minor adjustment to the mass of the full body model was done by equal relative adjustment to the mass of each body segment in order to further reduce the vertical residual force component. Several iterations of the residual reduction algorithm were performed until the residual forces and moments were considered sufficiently low (within limits judged as "good" according to the OpenSim documentation [13]). With the muscle set included, a static optimization algorithm, which minimizes the sum of squared muscle and actuator activations, was run for each time step of the running trial to determine individual muscle forces at each time step. In a final step, a joint reaction analysis was performed using the calculated muscle and actuator forces from the static optimization, and ground reaction force and moment data from the running trial as input.

\section{RESULTS}

The mass of the model was slightly reduced during the iterations of the residual reduction algorithm, reaching a final mass of $65.4 \mathrm{~kg}(-0.8 \%)$. The calculated joint reaction forces and moments, along with the measured ground reaction forces are presented in Fig. 2. The forces and moments were normalized with respect to the body weight and the time scale was normalized to $\%$ of gait cycle. The maximum and minimum forces and moments on the implant and the maximum measured ground reaction forces during the gait cycle are presented in Table 1 . The gait cycle consists of one stance phase for each leg lasting approximately $40 \%$ of the gait cycle, separated by an aerial phase lasting approximately $10 \%$ of the gait cycle. Maximum vertical ground reaction forces corresponded to $246 \% \mathrm{BW}$ and $243 \% \mathrm{BW}$ for the left 

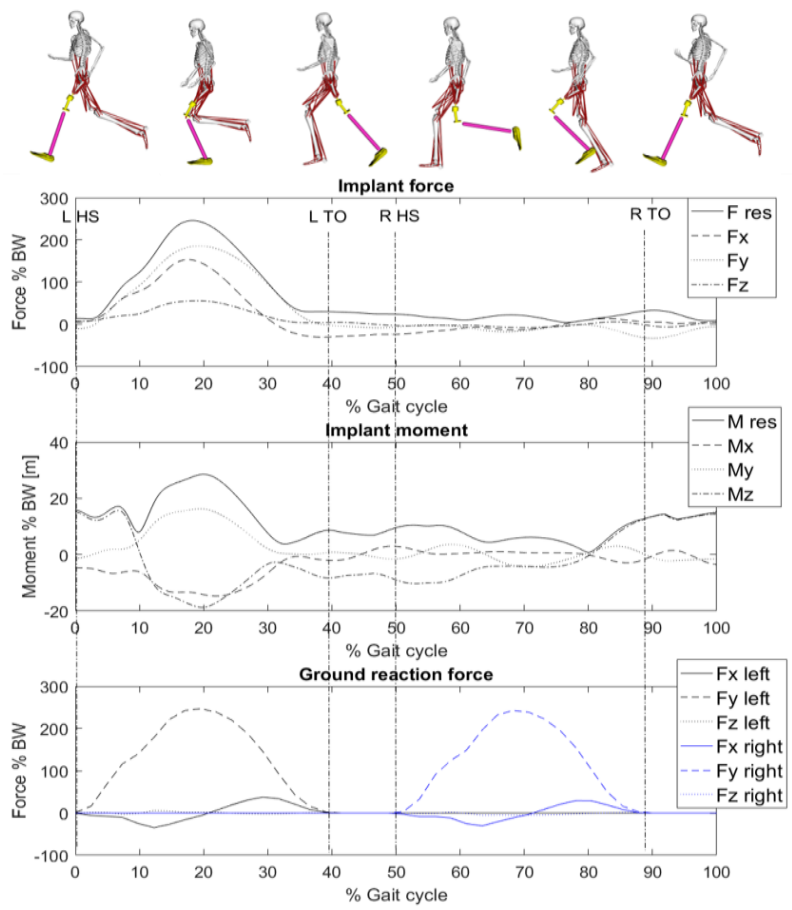

Figure II. Forces (top graph) and moments (middle graph) applied at the femur-implant joint during one gait cycle. The bottom graph shows the measured ground reaction forces for the same gait cycle of the running trial. Heel-strike and toe-off for each foot is indicated by the dashed, vertical lines.

and the right foot respectively and occurred $0.14 \mathrm{~s}$ after initial foot contact for each leg. A breaking force was measured in the first half of the stance phase (maximum $34.6 \% \mathrm{BW}$ for left leg and $30.4 \% \mathrm{BW}$ for the right leg) and propulsive phase was measured during the second half of the stance phase (maximum 37.6 \% BW for the left leg and $29.3 \% \mathrm{BW}$ for the right leg) for each leg respectively. A positive bending moment around the z-axis (posterior rotation) of the implant was observed during the first quarter of the stance phase reaching maximum value corresponding to $15.7 \% \mathrm{BWm}$. A negative bending moment (anterior rotation) was observed during the remaining part of the stance phase reaching a maximum negative value at mid-stance corresponding $-18.7 \%$ BWm. A positive torsional moment (lateral rotation) was noted during the entire stance phase reaching a maximum value of $16.2 \% \mathrm{BWm}$ at mid-stance. The bending moment around the $\mathrm{x}$-axis is negative (lateral rotation) during the stance phase reaching a maximum magnitude of $14.8 \% \mathrm{BWm}$ at midstance. Of the force components at the implant interface the ycomponent has the greatest magnitude reaching $186 \% \mathrm{BW}$ at mid-stance. The force component in the $\mathrm{x}$-direction reaches maximum value of $153 \% \mathrm{BW}$ at mid-stance.

\section{DISCUSSION}

The peak vertical components of the measured ground reaction forces in the load data used in this study have a similar magnitude as those reported in previous studies of abledbodied subjects [14]-[16]. At the implant interface, the moment with the highest magnitude is around the $\mathrm{z}$-axis during early to mid-stance. However, the peak moments around the $\mathrm{x}$ - and $\mathrm{y}$ - axes have almost equally large magnitudes. A linear extrapolation of the peak moments to a $100 \mathrm{~kg}$ individual,
Table I. Maximum and minimum forces and moments at the implant and maximum measured ground reaction forces for each foot during a single gait cycle. Forces and moments at the implant are presented in the local coordinate system of the implant. Ground reaction forces are presented in the global coordinate system. The timing within the gait cycle is indicated in parentheses.

\begin{tabular}{|c|c|c|c|c|c|c|}
\hline \multirow{2}{*}{$\begin{array}{l}\text { Forces } \\
\text { and } \\
\text { mome } \\
\text { nts } \\
\text { Compo } \\
\text { nent }\end{array}$} & \multicolumn{2}{|c|}{$\begin{array}{c}\text { Implant force } \\
\text { [\% BW] } \\
\text { (\% GC) }\end{array}$} & \multicolumn{2}{|c|}{$\begin{array}{c}\text { Implant } \\
\text { moment } \\
{[\% \text { BW m] }} \\
(\% \text { GC) }\end{array}$} & \multicolumn{2}{|c|}{$\begin{array}{c}\text { Ground } \\
\text { reaction force } \\
{[\% \text { BW] }} \\
(\% \text { GC) }\end{array}$} \\
\hline & Min & $\operatorname{Max}$ & Min & $\operatorname{Max}$ & $\begin{array}{l}\text { Max } \\
\text { left } \\
\text { foot }\end{array}$ & $\begin{array}{r}\text { Max } \\
\text { right } \\
\text { foot }\end{array}$ \\
\hline$X$ & $\begin{array}{l}-30.1 \\
(38.4)\end{array}$ & $\begin{array}{l}153 \\
(17.5)\end{array}$ & $\begin{array}{l}-14.8 \\
(22.0)\end{array}$ & $\begin{array}{l}3.01 \\
(49.3)\end{array}$ & $\begin{array}{l}37.6 \\
(29.2)\end{array}$ & $\begin{array}{l}29.3 \\
(78.1)\end{array}$ \\
\hline Y & $\begin{array}{l}-32.6 \\
(90.1)\end{array}$ & $\begin{array}{l}186 \\
(19.4)\end{array}$ & $\begin{array}{l}-4.47 \\
(70.5)\end{array}$ & $\begin{array}{l}16.2 \\
(19.6)\end{array}$ & $\begin{array}{l}246 \\
(19.6)\end{array}$ & $\begin{array}{l}243 \\
(68.3)\end{array}$ \\
\hline $\mathrm{Z}$ & $\begin{array}{l}-7.79 \\
(69.9)\end{array}$ & $\begin{array}{l}56.8 \\
(19.0)\end{array}$ & $\begin{array}{l}-18.7 \\
(19.7)\end{array}$ & $\begin{array}{l}15.7 \\
(6.72)\end{array}$ & $\begin{array}{l}5.82 \\
(12.3)\end{array}$ & $\begin{array}{l}2.49 \\
(58.5)\end{array}$ \\
\hline $\begin{array}{l}\text { Result } \\
\text { ant }\end{array}$ & $\begin{array}{l}4.50 \\
(76.6)\end{array}$ & $\begin{array}{l}246 \\
(18.2)\end{array}$ & $\begin{array}{l}0.76 \\
(80.0)\end{array}$ & $\begin{array}{l}28.5 \\
(20.0)\end{array}$ & $\begin{array}{l}247 \\
(19.6)\end{array}$ & $\begin{array}{l}243 \\
(68.3)\end{array}$ \\
\hline
\end{tabular}

which is the current weight limit for being eligible for boneanchored lower limb prostheses, would translate to $144 \mathrm{Nm}$, $158 \mathrm{Nm}, 182 \mathrm{Nm}$ for the $\mathrm{x}-, \mathrm{y}-, \mathrm{z}$-components, respectively, and a peak resultant bending moment of $228 \mathrm{Nm}$ (not considering the torsional component), which is above the fracture limit reported in [2] and within the range of reported peak moments in [3] and [4]. However, it should be noted that the cadaver femora used for the four-point-bending tests were obtained from a rather senior population (median age 73.5 years) compared with the likely younger population of TFAs who would consider running with their prosthesis.

\section{A. Limitations}

The musculoskeletal model of the current study assumes rigid body segments and thus does not consider any elastic, energy-recovering or peak-force attenuation effects which may be present in prosthetic feet or knee joints. Inverse dynamics is most suitable for estimation of joint moments during stance phase among lower limb amputees, since activities that involve little or no ground reaction forces are most sensitive to modelling inaccuracies [17], [18]. Therefore, although there are difficulties associated with the correct estimation of the inertial properties of the body segments, they do not affect the load scenario at the bone-implant as much during the stance phase as they do during the swing or areal phases. Another limitation is the accuracy of the muscle descriptions. The musculature of an amputated femur differs from that of a healthy lower limb. In this study, this was only taken into account by complete removal, or redirection of the geometry path, of muscles affected by the amputation. The individual muscle properties, such as maximum isometric force, optimal fiber length, unloaded tendon length, and physiological cross-sectional area (PCSA) were not altered for the redirected muscles although they could have been affected by the amputation. Nevertheless, since no muscles cross the bone-implant joint, they are unable to produce any compressive joint forces at this joint. Therefore, the muscle forces have limited impact on the loading scenario at the boneimplant interface, especially during the stance phase, when body segment accelerations are low and the external forces are the dominant terms in the force and moment equations. In this 
study, load data from a running trial of an able-bodied subject was used to calculate the forces and moments at the boneimplant interface of a TFA, although TFAs are not able to run with the same level of kinematic symmetry with current available lower limb prosthetic solutions. However, in the advent of more sophisticated robotic prostheses for lower limb amputees, there is potential for improved kinematic symmetry between the gait of the prosthetic and the anatomic limbs, with the ultimate goal of the prosthesis to restore full functionality of the missing limb. The results from this study provide relevant information about the load at the bone-implant interface in such a scenario.

\section{CONCLUSION}

The peak moments at the bone-implant interface could potentially be high enough to damage the bone or the implant at the bone-implant interface. However, care must be taken when evaluating forces and moments from inverse dynamics, and direct load measurements would be preferable if possible. Further studies should investigate relative effects of amputation height and prosthetic alignment, as well as consider the analysis of kinematic and ground reaction force data from subjects with an amputation.

\section{REFERENCES}

[1] A. Thesleff, R. Brånemark, B. Håkansson, and M. Ortiz-Catalan, "Biomechanical Characterisation of Bone-anchored Implant Systems for Amputation Limb Prostheses: A Systematic Review," Annals of Biomedical Engineering, pp. 1-15, 2018.

[2] B. Welke, C. Hurschler, M. Föller, M. Schwarze, and T. Calliess, "Stiffness and ultimate load of osseointegrated prosthesis fixations in the upper and lower extremity.," Biomed. Eng. Online, vol. 12, p. 70, 2013.

[3] B. Welke, M. Schwarze, C. Hurschler, T. Calliess, and F. Seehaus, "Multi-body simulation of various falling scenarios for determining resulting loads at the prosthesis interface of transfemoral amputees with osseointegrated fixation," J. Orthop. Res., vol. 31, no. 7, pp. 1123-1129, 2013.

[4] M. Schwarze, C. Hurschler, F. Seehaus, T. Correa, and B. Welke, "Influence of transfemoral amputation length on resulting loads at the osseointegrated prosthesis fixation during walking and falling," Clin. Biomech., vol. 29, no. 3, pp. 272-276, 2014.

[5] B. Burkett, J. Smeathers, and T. Barker, "Walking and running inter-limb asymmetry for Paralympic trans-femoral amputees, a biomechanical analysis.," Prosthet. Orthot. Int., vol. 27, pp. 3647, 2003.

[6] G. Mauroy, D. De Jaeger, J.-M. Vanmarsenille, and P. A. Willems, "The bouncing mechanism of running in a transfemoral amputee wearing a blade prosthesis.," Comput. Methods Biomech. Biomed. Engin., vol. 15 Suppl 1, no. sup1, pp. 357-9, 2012.

[7] M. S. Zahedi, W. D. Spence, S. E. Solomonidis, and J. P. Paul, "Repeatability of kinetic and kinematic measurements in gait studies of the lower limb amputee," Prosthet. Orthot. Int., vol. 11, no. 2, pp. 55-64, 1987.

[8] L. Frossard, J. Beck, M. Dillon, and J. Evans, "Development and Preliminary Testing of a Device for the Direct Measurement of Forces and Moments in the Prosthetic Limb of Transfemoral Amputees during Activities of Daily Living," JPO J. Prosthetics Orthot., vol. 15, no. 4, pp. 135-142, 2003.

[9] W. Lee, L. Frossard, and M. Zhang, "Load Mechanics in external and bone-anchored prostheses," in Biomedical Engineering Conference, 2006, pp. 71-74.

[10] W. C. C. Lee, L. A. Frossard, K. Hagberg, E. Häggström, R. Brånemark, J. H. Evans, and M. J. Pearcy, "Kinetics of transfemoral amputees with osseointegrated fixation performing common activities of daily living," Clin. Biomech., vol. 22, no. 6, pp. 665-673, 2007.

[11] S. R. Hamner, A. Seth, and S. L. Delp, "Muscle contributions to propulsion and support during running," J. Biomech., vol. 43, no. 14, pp. 2709-2716, 2010.

[12] S. L. Delp, F. C. Anderson, A. S. Arnold, P. Loan, A. Habib, C. T. John, E. Guendelman, and D. G. Thelen, "OpenSim: Opensource software to create and analyze dynamic simulations of movement," IEEE Trans. Biomed. Eng., vol. 54, no. 11, pp. 1940-1950, 2007.

[13] "OpenSim Documentation -RRA best practices." [Online]. Available: https://simtk-

confluence.stanford.edu/display/OpenSim/_RRA+Best+Practices. [Accessed: 25-Jan-2018].

[14] J. Hamill, B. T. Bates, K. M. Knutzen, and J. A. Sawhill, "Variations in ground reaction force parameters at different running speeds," Hum. Mov. Sci., vol. 2, no. 1-2, pp. 47-56, 1983.

[15] S. A. Bus, "Ground Reaction Forces and Kinematics in Distance Running in Older-Aged Men," Med. Sci. Sport. Exerc., vol. 35, no. 7, pp. 1167-1175, 2003.

[16] P. R. Cavanagh and M. A. Lafortune, "Ground reaction forces in distance running," J. Biomech., vol. 13, no. 5, pp. 397-406, 1980.

[17] A. B. Sawers and M. E. Hahn, "The potential for error with use of inverse dynamic calculations in gait analysis of individuals with lower limb loss: A review of model selection and assumptions," Journal of Prosthetics and Orthotics, vol. 22, no. 1. pp. 56-61, 2010.

[18] M. P. Dillon, T. M. Barker, and G. Pettet, "Effect of inaccuracies in anthropometric data and linked-segment inverse dynamic modeling on kinetics of gait in persons with partial foot amputation," J. Rehabil. Res. Dev., vol. 45, no. 9, pp. 1303-1316, 2008. 